\title{
Asset management using an extended Markowitz theorem
}

\author{
Reza Raei and Paria Karimi*
}

Department of Management and Accounting, University of Tehran, Tehran, Iran

\begin{tabular}{l}
\hline C H R O N I C L E \\
\hline Article history: \\
Received December 28, 2013 \\
Received in revised format April \\
152014 \\
Accepted April 182014 \\
Available online \\
April 21 2014 \\
\hline Keywords: \\
Markowitz Theorem \\
Tehran Stock Exchange \\
Genetic algorithm \\
Particle Swarm optimization
\end{tabular}

\section{A B S T R A C T}

Markowitz theorem is one of the most popular techniques for asset management. The method has been widely used to solve many applications, successfully. In this paper, we present a multi objective Markowitz model to determine asset allocation by considering cardinality constraints. The resulted model is an NP-Hard problem and the proposed study uses two metaheuristics, namely genetic algorithm (GA) and particle swarm optimization (PSO) to find efficient solutions. The proposed study has been applied on some data collected from Tehran Stock Exchange over the period 2009-2011. The study considers four objectives including cash return, 12-month return, 36-month return and Lower Partial Moment (LPM). The results indicate that there was no statistical difference between the implementation of PSO and GA methods.

C 2014 Growing Science Ltd. All rights reserved.

\section{Introduction}

Asset management is one of the popular issues among researchers and there are several studies on building a model to maximize the return and minimize the risk at the same time (Hübner, 2007; Jensen, 1969). Sharpe $(1966,1994)$ is one of the pioneers who developed a technique to examine the performance of an investment by adjusting for its risk. The ratio measures the risk premium per unit of deviation in an investment asset or a trading strategy as risk. Arugaslan et al. (2008) performed a study to evaluate the risk-adjusted performance of the largest US-based equity mutual funds based on rigorous analysis grounded in modern portfolio theory. Markowitz theorem (Markowitz, 1952, 1970) is one of the most well-known techniques to determine optimal investment strategies. The theory has been well studied under different conditions (Fabozzi et al., 2007). The standard Markowitz mean-variance model to portfolio selection incorporates tracing out an efficient frontier, a continuous curve presenting the tradeoff between return and risk. This frontier can be often determined via standard quadratic programming, categorized in convex optimization.

\footnotetext{
*Corresponding author.

E-mail addresses: pariakarimi@hotmail.com (S. Shahba) 
Chang et al. (2000), for instance, studied the problem of locating the efficient frontier associated with the standard mean-variance portfolio optimization model. They contributed to the original model by adding cardinality constraints, which limited a portfolio to be limited to a specified number of assets, and to apply limits on the proportion of the portfolio held in a given asset. They also explained the differences arising in the shape of this efficient frontier when such constraints imposed and solved the resulted model based on three heuristic algorithms, namely genetic algorithms, tabu search and simulated annealing for locating the cardinality constrained efficient frontier. They reported that the funds with the highest returns could lose their attractiveness once the degree of risk had been factored into the analysis. Alternatively, some funds may look very attractive once their low risk was taken into account.

Streichert et al. (2004) investigated the same portfolio optimization problem using evolutionary algorithms by considering the cardinality constrained. Maringer and Kellerer (2003) studied the same optimization of portfolios using a hybrid local search algorithm. Soleimani et al. (2009) extended the problem by including three options to the original model, which could lead Markowitz's model to a more practical one. They took into account the minimum transaction lots, cardinality constraints and sector capitalization proposed in this research for the first time as a constraint for Markowitz model. They explained that the new model could be stated as an Np-Hard problem and proposed a genetic algorithm to solve the resulted model.

\section{The proposed study}

Let $x_{i}$ be the number of shares purchased from the share $i, f_{1}$ to $f_{4}$ represent cash return, 12-month return, 36-month return and Lower Partial Moment (LPM), respectively. In addition, $y_{j}$ is a binary variables, which is one if an asset is selected and zero, otherwise. In addition, $l_{i}$ and $u_{i}$ are lower and upper bounds associated with each asset, and finally, $w_{i}$ is the relative weight of each asset. The problem statement is formulated as follows,

$\max z=\sum_{i=1}^{4} w_{i} f_{i}$

subject to

$\sum_{i=1}^{n} x_{i}=1$

$l_{i} y_{i} \leq x_{i} \leq u_{i} y_{i}$

$\sum_{i=1}^{n} y_{i}=m$

$x_{i} \geq 0, y_{i}=\{0,1\}$

The objective function $z$ maximizes the sum of weighted four objectives and weights are measured by decision maker. Eq. (2) represents the budget constraint, Eq. (3) and Eq. (4) are associated with cardinality constraints and Eq. (4) shows the number of assets, which must be included in the asset. Finally, Eq. (5) shows the nature of continuous and binary variables. In order to calculate LPM, the study uses the following,

$L P M_{\text {in }}=\frac{1}{m} \sum_{t=1}^{m}\left[\max \left(0,\left(h-R_{i t}\right)\right)\right]^{n}$

where $R_{i t}$ represents the return of $i^{\text {th }}$ asset at time $t$ and $h$ states target value of return. 
The results problem formulation is an NP-Hard problem and the optimal solution is not directly available when the size of the problem increases. Therefore, we need to use metaheuristics to find near optimal solutions. In this study, we use genetic algorithm (GA) and particle swarm optimization (PSO).

For GA implementation, we use two chromosomes, one, which handles $x_{i}$ and the other, represents binary variables, $y_{i}$, respectively. A new generation is created based on crossover operation where we use two-point interchange. In addition, the proposed study of this paper uses mutation to improve the performance of the proposed study (Goldberg, 1989; Holland, 1975).

Particle swarm optimization (PSO) has been a well-known method, which applies a swarm intelligence to detect the best solution (Kennedy \& Eberhart, 1995). The implementation of PSO for this paper uses the following notations,

\section{Table 1}

The parameters used for PSO method

\begin{tabular}{ll}
\hline Notation of PSO & Description \\
\hline$i:$ & Index for particles \\
\hline POP: & Population \\
\hline$n P o p:$ & Number of population \\
PAR[i]: & Position of particle $i$ \\
\hline$V E L[i]:$ & Velocity of particle $i$ \\
\hline GlobalBest: & Best global solution \\
\hline$w:$ & Inertia coefficient \\
$P B E S T[i]:$ & Best position of particle $i$ \\
$C_{1}:$ & Personal learning coefficient \\
$C_{2}:$ & Social learning coefficient \\
$R_{1}, R_{2}:$ & Random numbers generated between zero and one \\
\hline
\end{tabular}

The following steps are required to use PSO for the proposed method of this paper,

\section{Initialization}

Step 1. Select initial values,

Step 2. Setup initial values using some randomly generated data for all particles with zero value for velocity,

Step 3. Decode the solution and compute the combined objective function based on $\alpha \bar{C}+\beta \frac{\sum\left(W_{i}-\bar{W}\right)^{2}}{m}$,

Step 4. Select the particles with minimum cost and store its position as GlobalBest,

Step 5. Select the best personal position

Repeat steps 6 to 12 until termination criterion is met.

Step 6. Update velocity using Eq. (13) as follows,

$$
V E L[i](\text { new })=w . V E L[i](\text { old })+R_{1} .(P B E S T S[i]-P A R[i])+R_{2} .(\text { GlobalBest }-P A R[i])
$$

Step 7. Update each particle position based on Eq. (8)

$$
P O P[i](\text { new })=P O P[i](\text { old })+V E L[i](\text { new })
$$


Step 8. Similar to what we have done in step 3, evaluate position of each particle, update the best position of each particle and determine the best global solution.

Step 9. Perform a local search using of the three methods of Swap, Reversion and Insertion with equal probabilities as shown in Fig. 1.
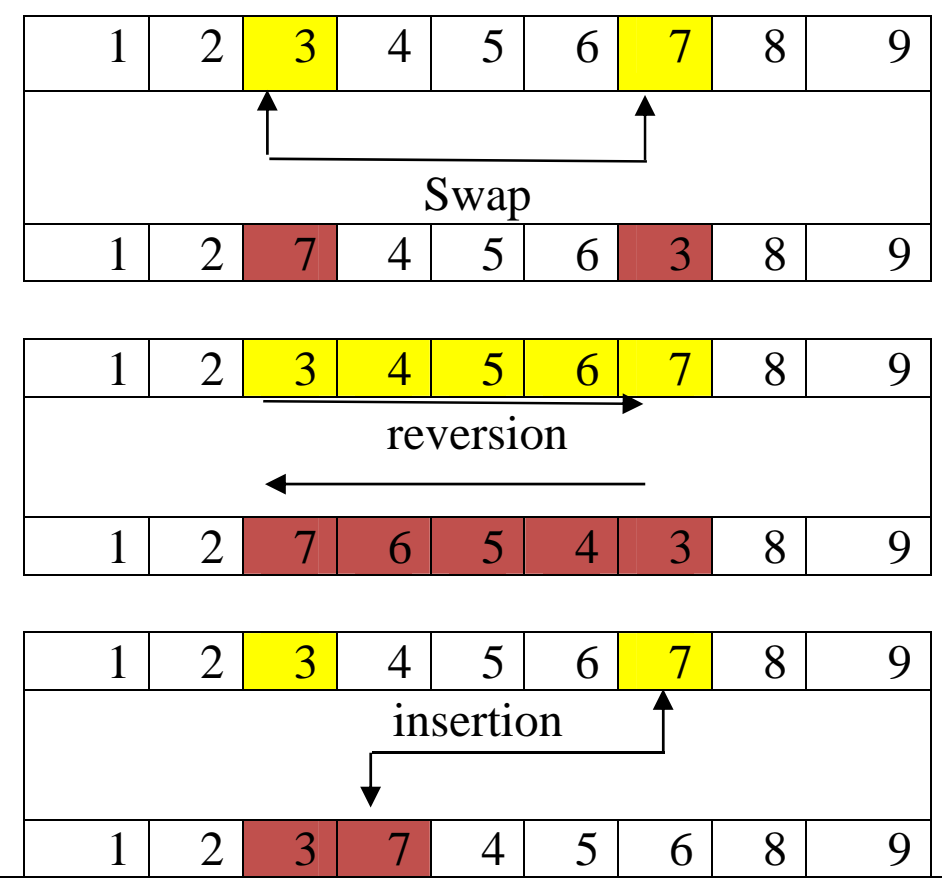

Fig. 1. The way of performing swap, reversion and insertion

Step 10. If the local search provides better solution, replace it with current solution, and update the best position of each particle

Step 11. Update the best global solution,

Step 12. Perform a local search on GlobalBest and update current solution.

\section{The results}

The implementation of GA in this paper uses the following parameters: Population $=50$, Rate of mutation $=0.35$, Tournament size $=48$. In addition, for PSO, we set velocity of each individual to $0.50, \mathrm{k}=0.05, \mathrm{c}_{1}$ and $\mathrm{c}_{2}=2.05$ and epsilon $=1000$. The proposed study considers three values of 10 , 15 and 20 as the number of assets and the lower and the upper bounds are set to 0.02 and 0.15 , respectively. The proposed study uses t-student test to find out whether there is any meaningful difference between the results of GA versus PSO. Table 2 shows details of our findings for 10 assets. As we can observe from the results of Table 2, there is not any meaningful difference between two methods. We have performed t-student test for out of sample numbers and the results did not indicate any difference between two methods, GA and PSO. Finally, we have repeated the process based on other criteria such as variance criterion and the results were similar. In other words, there is not any meaningful difference between the results of GA and PSO.

Table 2

The summary of t-student test between GA and PSO for 10 assets based on the measure of LPM

\begin{tabular}{|c|c|c|c|c|c|c|c|c|}
\hline & \multicolumn{5}{|c|}{ Paired Differences } & \multirow{3}{*}{$\mathrm{t}$} & \multirow{3}{*}{$\mathrm{df}$} & \multirow{3}{*}{ Sig. (2-tailed) } \\
\hline & \multirow[t]{2}{*}{ Mean } & \multirow[t]{2}{*}{ Std. Deviation } & \multirow[t]{2}{*}{$\begin{array}{l}\text { Std. Error } \\
\text { Mean }\end{array}$} & \multicolumn{2}{|c|}{$\begin{array}{l}\text { 95\% Confidence Interval of the } \\
\text { Difference }\end{array}$} & & & \\
\hline & & & & Lower & Upper & & & \\
\hline GA - PSO & 32.79849 & 344.00810 & 34.40081 & -35.46018 & 101.05716 & .953 & 99 & .343 \\
\hline
\end{tabular}


Table 3 shows details of our findings when there are 15 assets in our portfolio.

\section{Table 3}

The summary of t-student test between GA and PSO for 15 assets based on the measure of LPM

\begin{tabular}{|c|c|c|c|c|c|c|c|c|}
\hline & \multicolumn{5}{|c|}{ Paired Differences } & \multirow{3}{*}{$\mathrm{t}$} & \multirow{3}{*}{ df } & \multirow{3}{*}{ Sig. (2-tailed) } \\
\hline & \multirow[t]{2}{*}{ Mean } & \multirow[t]{2}{*}{ Std. Deviation } & \multirow[t]{2}{*}{$\begin{array}{l}\text { Std. Error } \\
\text { Mean }\end{array}$} & \multicolumn{2}{|c|}{$\begin{array}{l}\text { 95\% Confidence Interval of the } \\
\text { Difference }\end{array}$} & & & \\
\hline & & & & Lower & Upper & & & \\
\hline GA - PSO & 2.75647 & 25.88299 & 2.58830 & -2.37928 & 7.89222 & 1.065 & 99 & .289 \\
\hline
\end{tabular}

The results of Table 3 are similar to the results of Table 2 and there is not any meaningful difference between GA and PSO when there are 15 assets in portfolio. The results for out of sample also have indicated that there was not meaningful difference between two metaheuristics. The results of tstudent test based on other criteria are the same as this one and we did not find any meaningful difference between the implementation of GA versus PSO.

\section{Conclusion}

In this paper, we have presented an empirical investigation to determine asset allocation using a modified Markowitz theorem on data collected from Tehran Stock Exchange (TSE). Using historical data from TSE market, the survey has applied two metaheuristics, namely genetic algorithm and particle swarm optimization to find the asset allocation when the cardinality constraint was set 10,15 and 20. The results have indicated both methods were capable of providing near optimal solutions and there is statistically no meaningful difference between the results of genetic algorithm and particle swarm optimization.

\section{Acknowledgement}

The authors would like to thank the anonymous referees for constructive comments on earlier version of this paper.

\section{References}

Arugaslan, O., Edwards, E., \& Samant, A. (2008). Evaluating large US-based equity mutual funds using risk adjusted performance measures. International Journal of Commerce and Management, 17(1/2), 6-24.

Chang, T. J., Meade, N., Beasley, J. E., \& Sharaiha, Y. M. (2000). Heuristics for cardinality constrained portfolio optimisation. Computers \& Operations Research, 27(13), 1271-1302.

Fabozzi, F. J., Kolm, P. N., Pachamanova, D., \& Focardi, S. M. (2007). Robust portfolio optimization and management. John Wiley \& Sons.

Goldberg, D.E. (1989). Genetic Algorithms in Search, Optimization and Machine Learning. Addison Wesley Longman.

Holland, J.H. (1975). Adaptation in Natural and Artificial Systems. University of Michigan Press, Ann Arbor.

Hübner, G. (2007). How do performance measures perform?. The Journal of Portfolio Management, 33(4), 64-74.

Jensen, M. C. (1969). Risk, the pricing of capital assets, and the evaluation of investment portfolios. Journal of business, 42(2), 167.

Kennedy, J., \& Eberhart, R.C. (1995).Particle swarm optimization. In: Proceedings of the 1995 IEEE International Conference on Neural Networks, 4, 1942-1948.

Markowitz, H. (1952). Portfolio selection. The Journal of Finance, 7(1), 77-91.

Markowitz, H. M. (1970). Portfolio selection: efficient diversification of investments (Vol. 16). Yale University Press. 
Maringer, D., \& Kellerer, H. (2003). Optimization of cardinality constrained portfolios with a hybrid local search algorithm. OR Spectrum, 25(4), 481-495.

Sharpe, W. F. (1966). Mutual fund performance. Journal of Business, 39(S1), 119-138.

Sharpe, W. F. (1994). The Sharpe ratio. The Journal of Portfolio Management, 21(1), 49-58.

Soleimani, H., Golmakani, H. R., \& Salimi, M. H. (2009). Markowitz-based portfolio selection with minimum transaction lots, cardinality constraints and regarding sector capitalization using genetic algorithm. Expert Systems with Applications, 36(3), 5058-5063.

Streichert, F., Ulmer, H., \& Zell, A. (2004). Evolutionary algorithms and the cardinality constrained portfolio optimization problem. In Operations Research Proceedings 2003 (pp. 253-260). Springer Berlin Heidelberg. 